\title{
Mechanical behavior of a calcium phosphate ceramic bone graft used in the rehabilitation of a $\mathrm{C} 4$ human vertebra
}

\author{
Beltrán-Fernández, J.A.1, a, Hernández-Gómez, L.H.2,b Rodríguez-Cañizo, \\ R.G.1,c, Urriolagoitia-Calderón, G.2,f, Urriolagoitia-Sosa, G.3,g,González- \\ Revatú, A.4,d, , Dufoo-Olvera, M.5,e
}

\begin{abstract}
1Escuela Superior de Ingeniería Mecánica y Eléctrica (ESIME) Unidad Culhuacán, Av. Santa Ana No. 1000 Col. San Francisco Culhuacán C.P. 04430 Del. Coyoacán, México.

2 Escuela Superior de Ingeniería Mecánica y Eléctrica (ESIME) Unidad Zacatenco, U.P Adolfo López Mateos, Edificio 5, 3er Piso, Colonia Lindavista 07738 México, D.F., México.

3 Escuela Superior de Ingeniería Mecánica y Eléctrica (ESIME) Unidad Azcapotzalco, Av. de las

Granjas No. 682 Col. Santa Catarina Azcapotzalco, D.F. C.P. 02550, México.

4Hospital Regional ISSSTE 1ํ de Octubre, Av. Instituto Politécnico Nacional. Núm. 1669, Col.

Magdalena de las Salinas, 07760 Delegación Gustavo A. Madero, México.

${ }_{5}$ Hospital de Urgencias La Villa, Av. San Juan de Aragón, 07760 Del. Gustavo A. Madero, México.
\end{abstract}

ajbeltran@ipn.mx, bluishector56@ hotmail.com, c rgrodriguez@ipn.mx

Keywords: Cervical, Vertebrae, Stress, Calcium phosphate ceramic bone graft, Corporectomy.

Abstract. The main results of a static analysis with a finite element model of the cervical section between $\mathrm{C} 3$ - C5 of a human spine are reported. In this case, it is assumed that the element $\mathrm{C} 4$ is completely damaged and has to be replaced. Therefore, a bone graft was installed between the anterior side of C3 and C5. Besides, a cervical plate of $55 \mathrm{~mm}$. was fixed at the same side with 4 expansive screws. The resultant stresses caused by compression loads were analyzed and the displacements between the graft and adjacent vertebrae were calculated. Three loading conditions were applied: $80 \mathrm{~N}, 637.5 \mathrm{~N}$ and $6374.5 \mathrm{~N}$. The first one corresponds to the head weight. In the second case, it is assumed that the average patient weight is supported by those vertebrae, while in the last one; the compression load failure is applied on the vertebrae.

Results show that displacements were lower than $3 \mathrm{~mm}$ between the graft and the adjacent vertebrae. In accordance with the concept of spine stability after Müller [1], the arrangement is a stable one. Another advantage is that no wires are used in this surgical technique. Two more issues should be noticed. There is no risk that the plate may be broken and the geometry of the bone graft allows bone regeneration. These results are on line with those observed in preliminary experimental tests with porcine vertebrae.

\section{Introduction}

Diverse studies on cervical section of human spine show that some fractures of the vertebral body $[1,2,3,4,5,6]$ or a vertebral disc [7] after an accident are critical. Consequently, patients are involved in a rehabilitation process, which will take between 3 to 6 months, in order to return to their normal life. Nevertheless, when the vertebral body fails completely, an immediate medical attention is needed. For this purpose, the damaged zone is isolated. The vertebral body is replaced with a bony graft, by means of a Corporectomy technique [8]. In order to ensure the stability of the graft and make it easy a rehabilitation process of the vertebrae, a complex surgical operation is required. Thus, the objective is to simplify the orthopaedic procedure.

Different studies have analysed the cervical region C3 - C7, an example is [9]. In all the cases, the structural behaviour under compression is considered. It is not used a cervical plate or a bone graft [10]. Qualitative conclusions may be obtained in order to explain the mechanical behaviour of the cervical region. 
A different approach is required in order to analyze the influence of a cervical plate and a bony graft in the replacement of a damaged $\mathrm{C} 4$ vertebra. Under this work, the structural integrity of an arrangement with $\mathrm{C} 3-\mathrm{C} 5$ cervical section, in which $\mathrm{C} 4$ is replaced with a bony graft and cervical plate is studied.

\section{Statement of the problem.}

In modern surgical techniques, the damaged vertebral body is removed. Adjacent surfaces are prepared and a bone graft, previously conformed, is fixed. Following this process, it is necessary to include a cervical plate (Figure 1), and a wire is used on the posterior side of the spine (Figure 2).

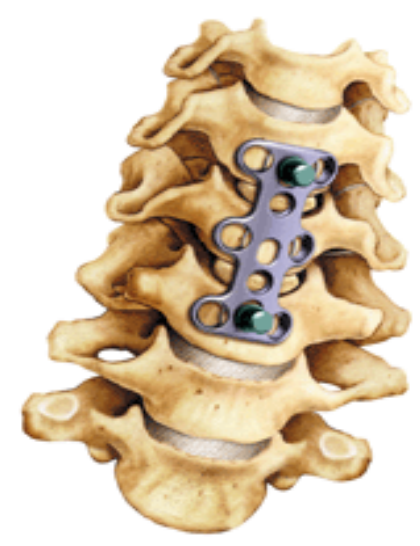

Fig. 1 Cervical plate used for a Corporectomy using an anterior side.

As a consequence, the patient has to use a collar, which supports and prevents movements, which affect the damaged zone. During the therapy period, several X-Ray plates are taken in order to study the behaviour of the bone graft, wire or cervical plate used. If the surgical medic considers that an adjustment is required, other surgical operations will be carried out. Reports indicate that a patient with a Corporectomy needs around 4 - 6 operations during this therapy [5].

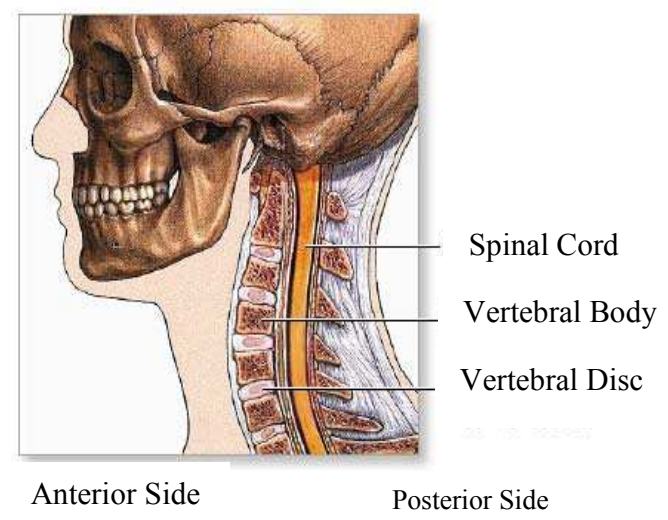

Fig. 2. Anterior and posterior spine sides of a human.

In this study, it is proposed to avoid the use of wires and include only a trapezoidal bone graft and cervical plate. In order to ensure structural integrity, the displacements among these elements should be lower than $3.5 \mathrm{~mm}$. 


\section{Numerical Analysis}

A Finite Element Model of C3, C4 and C5 cervical section has been developed, a bone graft replacement of $\mathrm{C} 4$ vertebra was introduced and a cervical plate manufactured by Ortosintese (model 3317/04), which increase stability, was also considered within the modelling. This model was created with Mechanical Desktop (figure 3) and ANSYS (figure 4). It has 95782 tetrahedral elements (SOLID 95) with 157633 nodes.

As mentioned above, three different compression loading conditions were considered, namely 80 $\mathrm{N}, 637.5 \mathrm{~N}$ and $6374.5 \mathrm{~N}$. The first one corresponds to the head weight. The second case is when the average patient weight is applied on the arrangement. While in the last, it is the failure compression load applied to the vertebrae.

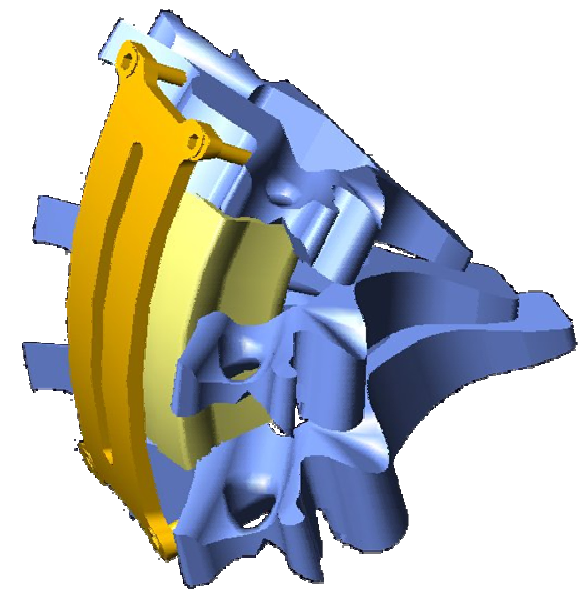

Fig. 3 3-D CAD Model of C3-C5 Cervical.

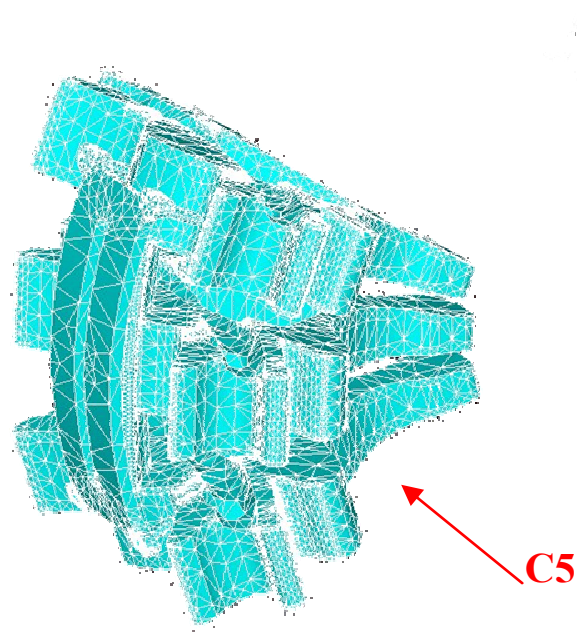

Fig. 4 FEM C3-C5 Cervical Model.

Figure 5 shows the compression load being applied on C3 vertebra while the nodes on the bottom surface of $\mathrm{C} 5$ are fixed.

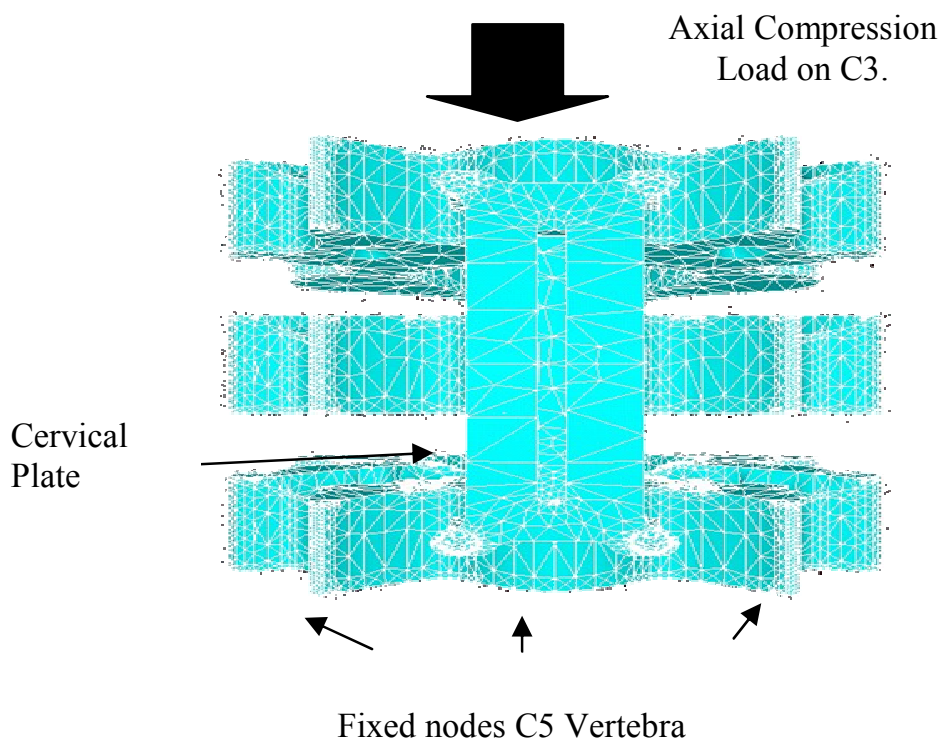

Fig. 5 Boundary Conditions for FEM Model 
The Mechanical properties considered for the materials are shown in table 1.

\begin{tabular}{|c|c|c|c|c|}
\hline & Property & Value & Units & Reference \\
\hline \multirow{2}{*}{ CORTICAL BONE } & Young Module & 12 & {$[\mathrm{GPa}]$} & \multirow{2}{*}[7]{} \\
\hline & Poisson's Ratio & 0.2 & & \\
\hline BONE GRAFT & $\begin{array}{l}\text { Maximum Compression Stress } \\
\text { Strength }\end{array}$ & $5-15$ & [MPa] & {$[12]$} \\
\hline \multirow{3}{*}{$\begin{array}{l}\text { CERVICAL PLATE } \\
\text { AND SCREWS } \\
\text { 3317/04 OS } \\
\text { (Ortosintese) } \\
\text { (Ti6A14V) }\end{array}$} & Young Module & 102 & {$[\mathrm{GPa}]$} & \multirow[b]{3}{*}{ [11] } \\
\hline & Poisson's Ratio & 0.3 & & \\
\hline & Yielding Stress Strength & 827 & {$[\mathrm{MPa}]$} & \\
\hline
\end{tabular}

Table 1. Mechanical Properties for the FEM Cervical Model.

\section{Obtained results}

Table 2 summarizes the obtained results. For the three cases, the stress level of the bone graft is low. For the most critical one, case 3 the resultant stress is below the top limit, so it is not expected the bone graft to be damaged. It should be mentioned as well that the resultant displacement among the surfaces of the vertebrae and the bone graft is lower than $3 \mathrm{~mm}$. This is in accordance with the criteria of Müller [1] and, this guarantees stability of the Spine.

\begin{tabular}{|c|c|c|}
\hline & $\begin{array}{c}\text { Von Mises Stress on the } \\
\text { Bone Graft [MPa }]\end{array}$ & $\begin{array}{c}\text { Maximum } \\
\text { Displacements [mm }]\end{array}$ \\
\hline CASE $1[80 \mathrm{~N}]$ & 0.124 & $6.857 \mathrm{e}^{-4}$ \\
\hline CASE $2[637.5 \mathrm{~N}]$ & 0.986 & 0.0054 \\
\hline CASE $3[6374.5 \mathrm{~N}]$ & 9.867 & 0.0546 \\
\hline
\end{tabular}

Table 2. Results for the 3 cases reported.

Because of the bone is graft is a synthetic material and its structure and composition is very similar to the bone tissue, a quick bone regeneration is warranted. The mechanical behavior of this material may be considered as orthotropic.

Regarding the Finite Element model, several materials are considered, namely bone, stainless steel, titanium alloy and bone graft. The applied loads generate stresses which are in the elastic range of all these materials. Besides, a common parameter is required to evaluate the severity of such stresses. Accordingly, the Von Mises criterion is used to evaluate the failure conditions of bone and metallic surgical materials. This makes easy the comparison of the results with those reported in the open literature. In the case of the bone graft used in this arrangement, the maximum principal stress is $9.867 \mathrm{MPa}$, which is lower than $15 \mathrm{MPa}$. 
Figure 6 shows Von Mises stresses, when the $6374.5 \mathrm{~N}$ compression load is applied. The critical zones are those adjacent to the contact points. The resultant maximum stress in this case was 9.867 $\mathrm{MPa}$, which is lower than compression stress failure of the cortical bone.
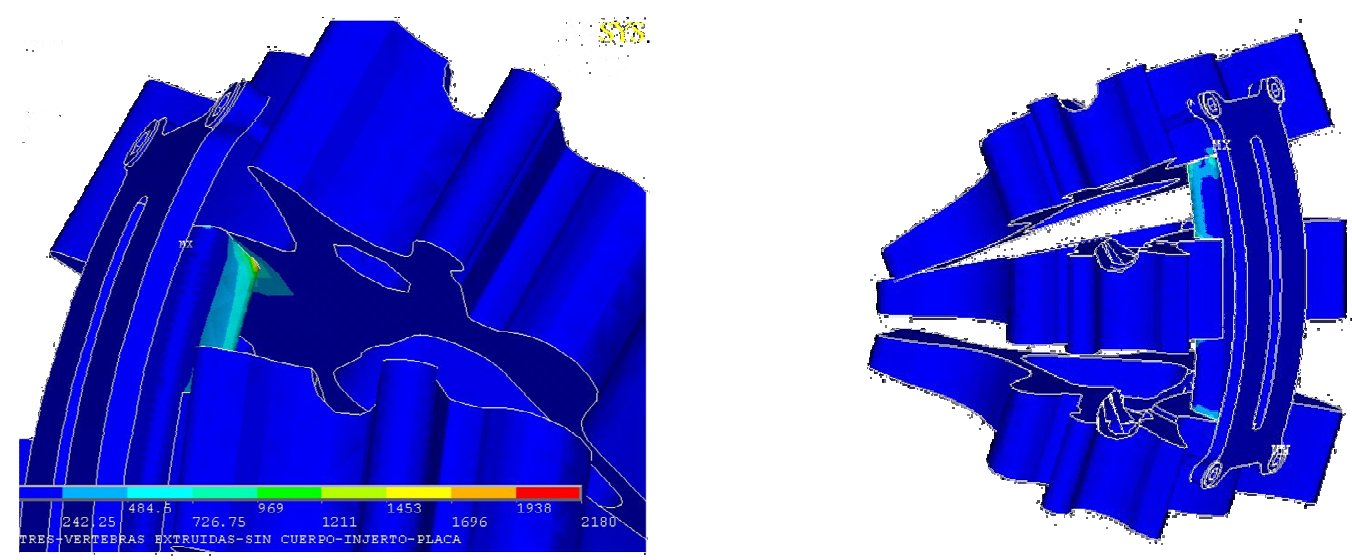

Fig. 6 Von Mises Stresses generated for the FEM Cervical Model.

The inclusion of a cervical plate is utmost importance. It was found that under the bone graft failure conditions, the compression stress obtained $(9.867 \mathrm{MPa})$ is within the allowed limit of failure. As a result it may be considered that the maximum allowed load is around $6375 \mathrm{~N}$. At the same time, the cervical plate is contributing in the structural stability of the arrangement. This is very important, because the bony manufacturers recommend that the compression load should be reduced as much as possible, because of the material fragility.

In accordance with the point of view of the orthopedist, the cervical fusion is benefited, based on the geometry of the bone graft, as it is a wedge that reduces the displacements among vertebral body surfaces of $\mathrm{C} 3$ and $\mathrm{C} 5$.

\section{Conclusions}

The displacements on the vertebrae surfaces are smaller than those suggested by Müller [1]. Besides, the resultant stresses show that this arrangement has a good structural integrity. For the bone graft, the stresses were lower than those reported in the open literature [12]. While for the cortical bone of the cervical vertebra it is not expected it to be damaged, because of the same criteria [10]. In accordance with the opinion of the orthopedist, this situation is desired, because the complexity of the surgical procedure is reduced, as no wires are introduced in the arrangement. Furthermore, the resultant stability allows bone regeneration.

In a second part of this work, to be published later, experimental analysis has been carried out with porcine cervical vertebrae. Preliminary results show that the numerical results are in accordance with those obtained experimentally.

\section{Acknowledgements}

The grants that supported this work were given by Instituto Politécnico Nacional and Hospital ISSSTE $1^{\circ}$ de Octubre. They are kindly acknowledged. 


\section{References}

[1] Müller, W., Manual of internal fixation. 3rd ed, Científico-Médica (1992)

[2] Yoganandan, N. \& Et. al. Epidemiology and Injury biomechanics in motor vehicle related trauma to the human cervical spine, SAE 892438, p. 223-241, (1989)

[3] Huelke, D. \& Et. al., Cervical injuries suffered in automotive crashes, J. Neurosurgery, 54: 316322. (1981)

[4] Thorson, J., Neck injuries in road accidents, Scand. J. Rehabilitation Med, 4, p.110-113. (1972)

[5] Holly, L. \& Et. al., Cervical spine trauma associated with moderate and severe head injury: incidence, risk factors, and injury characteristics. J Neurosurgery Spine 96:S285-91. (2002)

[6] Lowery, D, \& Et. al. Epidemiology of Cervical Spine Injury in Victims, Ann. Emergency Medicine, 38 (1) 12-16. (2001)

[7] M. F. Carvajal Romero, J. Nieto Miranda, R. Rodríguez Cañizo, M. Dufoo Olvera, L. H. Hernández Gómez, G. Urriolagoitia Calderón y A. Minor Martínez. Analysis of compressive stresses on the spine with intervertebral disk injury: Numerical-experimental study on a porcine specimen, Acta Ortopédica Mexicana, vol. 19, suplement 1, S6-S10. (2005)

[8] Mattar, S., Cirugía de la columna vertebral, Cirujano de la columna, centro médico vital, Carrera 51 B No. 94 - 334, Barranquilla - Colombia. (2005)

[9] Beltrán, J., Hernández Gómez, LH, Rodríguez Cañizo, R., Urriolagoitia Calderón, G., Gonzalez Rebatú, A., Dufoo Olvera, M., Distribución de esfuerzos por la acción de cargas de compresión en la vértebra cervical C5, empleando el método del elemento finito, Científica, Vol. 9, Num 3, Julio Septiembre, p.135-142, México. (2005)

[10] Moore, Ch. \& Et. al., The evaluation of a biphasic calcium phosphate ceramic for use in grafting long-bone diaphyseal defects, J. Orthop Res, 5:356-365. (1987)

[11] ORTOSINTESE, Products Catalogue, Rua Friedrich Von Voith, 896 - Jaragua, Brasil. (2006)

[12] Trecant \& Et. Al., Influence of post-implantation phyco-chemical changes in a macroporous ceramic on its mechanical strength, Journal of Materials: Materials in Medicine 7, p. 227-229. (1996) 